\title{
Electromagnetic Transparency of Composites of Unsaturated Polyester and Nanolignin: Morphological and Surface Energy Considerations
}

\section{Mayu Suzuki}

Meisei University School of Science and Engineering Graduate School of Science and Engineering:

Meisei Daigaku Riko Gakubu Daigakuin Rikogaku Kenkyuka

Annet Kondor

Surface Measurement Sytems

\section{Yuma Sakuraba}

Meisei University School of Science and Engineering Graduate School of Science and Engineering:

Meisei Daigaku Riko Gakubu Daigakuin Rikogaku Kenkyuka

\section{Orlando J. Rojas}

UBC: The University of British Columbia

Mariko Ago ( $\square$ mariko.ago@meisei-u.ac.jp )

Meisei University - Hino Campus: Meisei Daigaku https://orcid.org/0000-0001-5258-4624

\section{Research Article}

Keywords: spray drying method, millimeter frequency region, bio-based devices

Posted Date: June 1st, 2021

DOl: https://doi.org/10.21203/rs.3.rs-556483/v1

License: (c) (1) This work is licensed under a Creative Commons Attribution 4.0 International License. Read Full License 


\section{Electromagnetic transparency of composites of}

2 unsaturated polyester and nanolignin: Morphological

3 and surface energy considerations

4

5

6

7

Mayu Suzuki ${ }^{1}$, Anett Kondor ${ }^{2}$, Yuma Sakuraba ${ }^{1}$, Orlando J. Rojas ${ }^{3,4}$, Mariko Ago ${ }^{1 *}$

${ }^{1}$ Department of Interdisciplinary Science and Engineering, Meisei University, Hino, Tokyo 191-8506 Japan,

${ }^{2}$ Surface Measurement Systems Ltd., Rosemont Rd, Wembley, London HAO 4PE, UK

${ }^{3}$ Bioproducts Institute, Departments of Chemical \& Biological Engineering, Chemistry and Wood Science, University of British Columbia, Vancouver V6T 1Z3, Canada

${ }^{4}$ Department of Bioproducts and Biosystems, Aalto University, Espoo 02150, Finland

* Authors for correspondence: (M.A.) mariko.ago@meisei-u.ac.jp

Nanoparticles, LNPs, aerosol flow, dielectric property, gas inverse chromatography, surface energy, wave transparent

\section{Abstract}

We introduce a simple spray drying method for the scaleup production of spherical organic (lignin) microparticles with controlled size distribution $(0.85$ to $1.57 \mu \mathrm{m})$. We assess the surface energy of the lignin particles by inverse gas chromatography and determine its role in nanocomposites synthesized from unsaturated polyester. Such nanocomposites are shown to be irradiation transparent (millimeter frequency region). The permittivity and $\tan \delta$ of the composite material reached values between 0.01 and $3.1(28 \mathrm{GHz})$ with 10 per hundred resin filler content. Vinyl groups were introduced on the surface of the particles to achieve enhanced interfacial adhesion, and resulted in a reduced relative permittivity (2.75). Together with wave 
interactions, the mechanical and thermal properties of the composites are placed in perspective, opening new opportunities in next generation bio-based devices for $5 \mathrm{G}$ high-speed communication.

\section{Introduction}

Technical lignins are isolated from the wood biomass by using processes such as Kraft, soda, and sulfite pulping, which generate Kraft and alkali lignin as well as lignosulfonates, respectively.(Kai et al. 2016) During the efficient isolation protocol at pulping process, lignin molecules are altered by chemical reactions(Chakar and Ragauskas 2004) (Gierer 1980) via cleavage of inter-unit linkages in the native macromolecule, including $\beta-\mathrm{O}-4^{\prime}, \alpha-\mathrm{O}-4^{\prime}, \beta-\beta^{\prime}, 5-$ $5^{\prime}$ bonds and associated formation of new covalent bonds. Such process leads to be distinctly diverse lignin profiles, for instance, as far as molecular structure, alkyl-aryl ether content, degrees of secondary condensation, and molecular weight.(Sjostrom 1993) Isolated lignin represents an important and abundant biopolymer resource the behavior of which is highly predictable and adaptable based on its functionality and modifiability.(Glasser 2019) Despite its attributes (i.e., low cost, abundance, biodegradability, non-toxicity), valorization of technical lignins may be challenged by their molecular structure and the isolation processes,(Berlin and Balakshin 2014) e.g., given the changes in physico-chemical properties. To overcome the drawbacks associated with their diversity, developing spherical colloidal particles, herein called 'nanolignin', is an appealing option. Indeed, molecular assemblies into sizes ranging from the nano- to micron scales, can be employed as a new class of materials with interesting properties (microstructure and surface chemistry). Because of their large surface-to-volume ratio, nanolignin can have a great influence on the physicochemical properties of materials. In fact, the field of polymer nanoparticles is quickly expanding and 
playing a pivotal role in a broad spectrum of areas;(Rao and Geckeler 2011)'(Khan et al. 2019) the same can be said for those derived from lignin.(Abbati de Assis et al. 2018)

Nanolignin has been previously synthesized by precipitation methods initiated with electrolyte(Fritz et al. 2017), acids(Frangville et al. 2012), $\mathrm{CO}_{2}$ saturation(Myint et al. 2016), continuous solvent exchange,(Qian et al. 2014) and dialysis(Lievonen et al. 2016), as well as by sonication(Gilca et al. 2015) and emulsion templating methods(Nypelö et al. 2015). Studies related the synthesis protocols and their applications are referred to in available review articles.(Österberg et al. 2020)'(Ago et al. 2017) The physical properties of these particles, such as hydrophobicity, surface charge, and stability, are dependent on the type of lignin precursor and the synthesis procedure. The wide range of morphological properties of nanolignin makes it suitable for controlled functionalization for environmentally benign applications. Additionally, by varying the synthesis conditions (solvent/anti-solvent, atmosphere, temperature, etc.) and sources (Kraft, sulfonate, organosolv, milled wood), the surface chemistry of the lignin, and consequently surface energy of the resultant particles, can be conveniently controlled. Therefore, understanding surface energy of nanolignins is critical to develop sustainable nanomaterials as well as to tailor their performance.

In recent years, dynamic sorption methods have become increasingly important, including dynamic sorption techniques such as inverse gas chromatography (IGC).(Lloyd et al. 1989) Therein, a solid adsorbent of unknown surface energy is placed in a column, in contact with a selected gas-phase, used as adsorbate. As in analytical gas chromatography, the retention time is measured and converted into a retention volume, which is directly related to several physicochemical properties of the absorbent). Key thermodynamic parameters, such as surface energy, heat sorption and kinetic parameters (diffusion constant and the activation energy) can be determined following the uptake via physisorption on the surface area and considering the 
heterogeneity profiles of the biomaterial.(Belgacem et al. 1995) (Beaumont et al. 2017) The lignin spherical particles, firstly synthesized by an aerosol flow method, exhibited very interesting characteristics(Ago et al. 2016a) and were found to be effective in the stabilization of oil-in-water $(\mathrm{O} / \mathrm{W})$ Pickering emulsions. The results were related to the surface hydrophilicity of the solid emulsifier (Kraft lignin nanoparticles, KLNP). Overall, understanding of the surface energy of the lignin particles is essential in considering their applications. Hence, here we assess the surface energy of lignin spherical particles obtained though aerosol flow method by inverse gas chromatography.

The discussed KLNP and their surface energy are factored in applications related to millimeter waves, relevant to high-speed, large-capacity communication, a field of recent rapid growth. Wave-transparent polymer composites that can transmit electromagnetic waves at a certain frequency have been widely used, for example, in antenna windows, microwave relay stations, radomes, among others. In this sense, polymeric materials commonly possess low dielectric constant and good mechanical properties and are favored for their processability compared to inorganic materials.(Blattmann and Pratsinis 2019)'(Wang et al. 2020) Electromagnetic losses are mainly due to the polarization phenomenon of the medium in the external electric filed, i.e., electric, atomic, ionic, orientation, and interfacial polarization.(Wang et al. 2020) In composite materials, the interface between filler and matrix is prone to interfacial polarization. A poor interfacial adhesion would cause multiple reflections and losses of electromagnetic waves at the interface.(Tang et al. 2021)' (Hu and Ishikawa 2020) Thus, in order to achieve nanocomposites with low dielectric constant $(\varepsilon)$ and dielectric loss tangent $(\tan \delta)$, it is crucial to reduce interfacial polarization by reducing the polarization molecular density or by improving the interfacial adhesion between the filler and the matrix.

$$
\text { We propose a method that departs from efforts reported so far by the fact that dry, perfectly }
$$
spherical, non-fused lignin particles are used for their high structural integrity. Considering 
these characteristics, we apply KLNP as reinforcing filler in nanocomposites with or without surface modification and using a low-polarity functional group containing silane nanofillers in an unsaturated polyester matrix. The dielectric and mechanical properties, as well as thermal stability are evaluated aiming to provide a rationale for a new class of nanocomposites for uses in $(5 \mathrm{G})$ communication network.

In this study, firstly of its kind, we unveil the influence of precursor concentration on surface tension, particle formation and yield. The surface energy of the lignin particles is assessed via gas inverse chromatography and applied as a reinforcing filler for nanocomposites to

111 demonstrated a wave transparent material in the millimeter frequency region, relevant to 5G

112 high-speed communication.

\section{Experimental}

115 Materials. Kraft lignin (Indulin AT, Ingevity, USA) was used as received. Polyester resin 116 (FLH-350R, U-pica, Co., Ltd. Japan), a curing agent (Parmek N, NOF corporation, Japan), 117 Trichlorovinylsilane (TVCS) (Sigma-Aldrich, St. Louis, MO, USA), dimethyl formamide 118 (DMF), and toluene (Wako Fujifilm, Osaka, Japan) were used as supplied.

119 Synthesis of KLNP and surface modification. The synthesis of spherical particle of lignin has been discussed in our previous reports.(Ago et al. 2016b)' (Kämäräinen et al. 2019)' (Abbati de Assis et al. 2018) Briefly, Kraft lignin was dissolved in DMF at a concentration of $5 \%$ and above. The experimental set up used to synthesize the particles included a nebulizer, a heated reactor, and a cyclone collector. The generated lignin droplets at the nebulizer were suspended on nitrogen or air flow ( $3 \mathrm{l} / \mathrm{min})$ and carried to a heated laminar flow system that was kept at $153{ }^{\circ} \mathrm{C}$; finally, dried lignin particles were collected with a cyclone. In this work, another set up for synthesis spherical particles from lignin/DMF solution was applied, e.g., to increase the 
128 fluid nozzle atomization, a heated reactor, and a cyclone collector. In this method, the concentration of lignin solution ranged from 1 to $10 \%$ and the processing condition included

$130160{ }^{\circ} \mathrm{C}$, atomizing pressure of $0.16 \mathrm{MPa}$ and flow rate of $0.27 \mathrm{l} / \mathrm{min}$. The original Kraft lignin

131 powder and the synthesized spherical lignin particles thereafter denote as KL and KLNP, 132 respectively.

133 Surface tension, surface energy and acid-base chemistry. The surface tension of all the 134 solutions of lignin in DMF was measured with a du Nouy ring tensiometer (Surface tension 135 metre, Ito Seisakusyo, Co. 1td., Japan) operated at room temperature. The analyses for the 136 surface energy of KL and KLNP were carried out using inverse gas chromatography (iGC 137 Surface Energy Analyser). The data were analysed using both standard and advanced SEA 138 Analysis Software. About $100 \mathrm{mg}$ of the samples were packed into individual iGC silanised 139 glass column, and were run at a series of surface coverages with alkanes and polar probe 140 molecules to determine the dispersive surface energy $\left(\gamma_{S}{ }^{\mathrm{D}}\right)$ as well as the acid-base free energy 141 of adsorption $\left(\Delta G_{S P}\right)$. The sample column was pre-conditioned for $2 \mathrm{~h}$ at $30^{\circ} \mathrm{C}$ and $0 \% \mathrm{RH}$ 142 with $10 \mathrm{ml} / \mathrm{min}$ helium carrier gas. The experiment was conducted at $30{ }^{\circ} \mathrm{C}$ with $10 \mathrm{ml} / \mathrm{min}$ 143 total helium flow rate, and using methane for dead volume corrections. BET specific surface 144 area of the samples was determined via physical adsorption of octane molecules using the IGC145 SEA unit.

146 KLNP treatment. 5\% KLNP suspension in toluene containing $125 \mathrm{ppm}$ water was 147 prepared. Then $625 \mathrm{ppm}$ trichlorovinylsilane were added and agitated for $18 \mathrm{~h}$ at $40{ }^{\circ} \mathrm{C}$. The 148 treated KLNP were filtered and rinsed with toluene several times followed by distilled water.

149 The treated particles were dried at room temperature and then in vacuo at $100{ }^{\circ} \mathrm{C}$. The treated 150 KLNP is herein denote as V_KLNP.

151 Preparation of KL or KLNP/unsaturated polyester composites. Given amounts of KL or

152 KLNP, 0, 5, 10, 20, 30 per hundred resin (phr), were dispersed in the precursor solution of 
153 polyester resin, containing unsaturated polyester, styrene, methyl methacrylate, and maleic anhydride and sonicated (sonication bath) for 3-5 min and then further mixed with a planetary mixer with the combination of planetary mixing and defoaming modes (ARE-310, Thinky Co., Ltd. Japan) to obtain homogeneous suspensions without agglomeration of lignin and free of air bubbles. Then, $1 \mathrm{wt} \%$ curing agent was added, and the suspension was mixed again with a planetary mixer for $3 \mathrm{~min}$. The suspension was poured on Teflon sheet and allowed to cure at room temperature for $20 \mathrm{~h}$ followed by a post-curing process at $40{ }^{\circ} \mathrm{C}$ for $2 \mathrm{~h}$. KLNP/Polyester composites were observed using a FE-SEM (S-4700, Hitachi, Co. Ltd., Japan). The samples were placed on a carbon tape followed by a metal coating with $\mathrm{Pt} / \mathrm{Pd}$ to guarantee the secondary electrons on the samples during the observation. The images were obtained at $1.6 \mathrm{kV}$. The particle size and the distribution were estimated from SEM micrographs by using Fiji Image J.

167 Bending Tests: The mechanical properties of the composites containing KL or KLNP 168 compositions, were performed by three-point bending tests (STB-1225L (A\&D Co., Ltd. 169 Tokyo, Japan)). The dimensions of the specimens were $30 \mathrm{~mm}$ in length, $14 \mathrm{~mm}$ in wide, and

$1702 \mathrm{~mm}$ in height. The crosshead speed was set to $1 \mathrm{~mm} / \mathrm{min}$ for all the test and the applied force 171 and the strain were monitored until the specimen break. The modulus was calculated from each 172 S-S curve. The values for all the samples were averaged over three to five specimens. All the 173 specimens were preconditioned at $20{ }^{\circ} \mathrm{C}$ and $65 \% \mathrm{RH}$ before the measurement.

174 Thermal analysis: The thermal properties for all the composites were examined by 175 thermogravimetry (Themo plus, TG8120, Rigaku Co., Ltd., Japan) (TG-DTA) from r.t to 800 $176{ }^{\circ} \mathrm{C}$ under air flow, $0.4 \mathrm{l} / \mathrm{min}$ with heating rate, $10{ }^{\circ} \mathrm{C} / \mathrm{min}$. 
177 Dielectric measurement: The dielectric constant $(\varepsilon)$ and dielectric loss tangent $(\tan \delta)$ values

178 of the samples were measured using a dielectric analyzer (Anritsu MS46122A Vector Network

179 Analyzers) at $24{ }^{\circ} \mathrm{C}$, relative humidity $49 \%$. The corresponding specimen dimension was 30

$180 \mathrm{~mm} \times 30 \mathrm{~mm} \times 0.8 \mathrm{~mm}$. Three points in each sample were randomly selected for measurement.

181

182 Table 1 Concentration of lignin in the precursor solution and diameter and yield of the 183 resultant particles

184

\begin{tabular}{ccccc}
\hline Entry & $\begin{array}{c}\text { Concentrati } \\
\text { on, wt\% }\end{array}$ & \multicolumn{2}{l}{ Particle size, } & Yield, g/100ml \\
\hline 1 & 1 & 0.85 & \pm 0.04 & 0.15 \\
2 & 3 & 1.00 & \pm 0.06 & 0.15 \\
3 & 5 & 1.26 & \pm 0.05 & 0.34 \\
4 & 7.5 & 1.57 & \pm 0.04 & 1.94 \\
5 & 10 & 1.13 & \pm 0.07 & 3.11 \\
\hline
\end{tabular}

186

187

188

\section{Results and Discussion}

190 KLNP was synthesized with a spray dryer using the respective precursor solution at 1, 3, 5,

1917.5 , and $10 \%$ concentration. Table 1 shows the yield of KLNP, which was in the range 15-

$19230 \%$ based on consumed precursor solution and after running the instrument for the given

193 time. The yield increased with increasing the concentration of the lignin solution. Note that the

194 KLNPs yield was underestimated due to the large sample loss during the synthesis and

195 collection, within a short period of running time. For the tested concentration range, the mean

196 particle diameter ranged from 0.85 to $1.57 \mu \mathrm{m}$ and it increased with the concentration. This can

197 be explained by the increased viscosity of the precursor solutions, which produced larger 
198 droplets from the nozzle, under the given pressure. However, when a $10 \%$ precursor solution

199 was used, the particle size was decreased to $1.13 \mu \mathrm{m}$. No significant change in surface tension

200 was observed over the range of concentration tested; hence, no major effect on the particle size

201 and distribution was expected (Figure 1S). The particle size distributions and the corresponding

202 SEM images obtained from the various precursor concentration are compared in Figure1. The

203 particle size and the particle size distribution of KLNP obtained from the precursor solutions,

204 from the given concentrations, was analyzed by measuring approximately 200 particles over

205 several SEM images (Image J software).

206

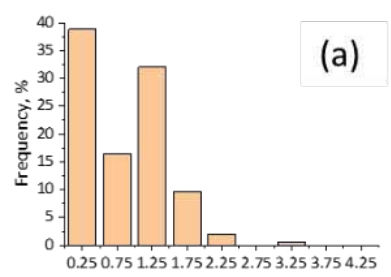

Diameter, $\mu \mathrm{m}$

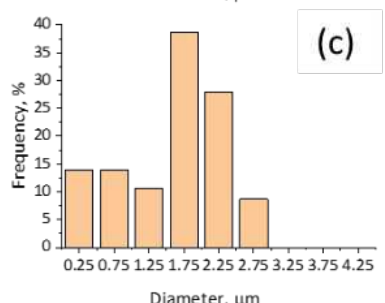

Diameter, $\mu \mathrm{m}$

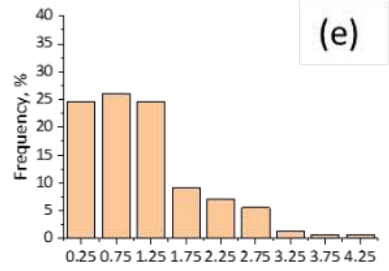

207

208

209

210

211

212

213

214 The particles were smooth and spherical. As the solution concentration of the precursor was

215 increased, the most frequent particle size shifted toward larger diameters, namely, from $\sim 0.5$ (b)
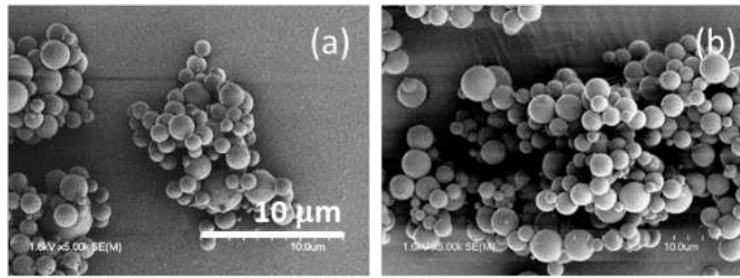

(d)
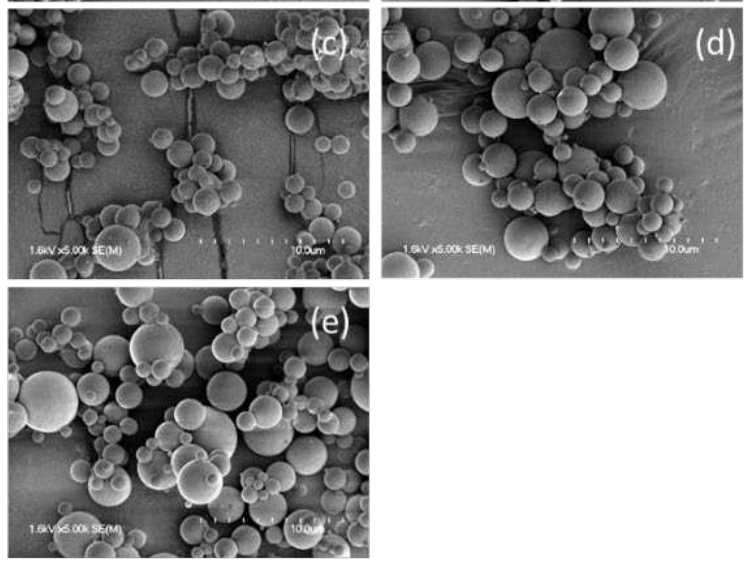

(4)

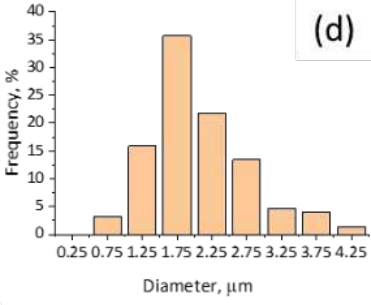

e)

Figure 1. Particle size distribution and SEM micrographs for KLNP obtained from KL precursor solutions at initial concentrations of (a) 1, (b) 3, (c) 5, (d) 7.5, and (e) $10 \%$. Scale bar in SEM images, $10 \mu \mathrm{m}$. 
$216 \mu \mathrm{m}$ for 1 and $3 \%$ solutions to $1.5 \sim 2 \mu \mathrm{m}$ for 5 and $7.5 \%$ solutions. Using a $10 \%$ solution, the

217 number density (frequency) of the smaller particles of $<1.5 \mu \mathrm{m}$ increased, which contributed

218 to a reduction in the average particle size. Overall, the most uniform particles were obtained

219 from the $5 \%$ precursor solution. Although monodisperse size particles may be difficult to

220 obtain via an aerosol flow process, where the precursor solution is atomized into small droplets

221 followed by evaporation through a heating process into molecular assembled, the average

222 particle size and distribution was controlled by varying the concentration of the precursor

223 solution.(Ago et al. 2016b)' (Ago et al. 2017) In order to investigate the surface energy for

224 KLNP, the particles obtained from the precursor solution with $5 \%$ concentration were used.

225 The surface energies of KL and KLNP were evaluated by gas inverse chromatography. This

226 technique allows to assess differences in surface energy and surface chemistry of samples that

227 are known to affect processes involving interfacial interactions, such as nanocomposites,

228 coatings, and adhesions. (Klapiszewski et al. 2017), (Strzemiecka and Voelkel 2012), (van

229 Asten et al. 2000) Dispersive $\left(\gamma_{\mathrm{S}}^{\mathrm{D}}\right)$, acid-base $\left(\gamma_{\mathrm{S}}^{\mathrm{AB}}\right)$ and total surface energy $\left(\gamma_{\mathrm{S}}^{\mathrm{T}}\right)$ profiles

230 obtained directly from the IGC, for both samples, are shown in Figure 2. 

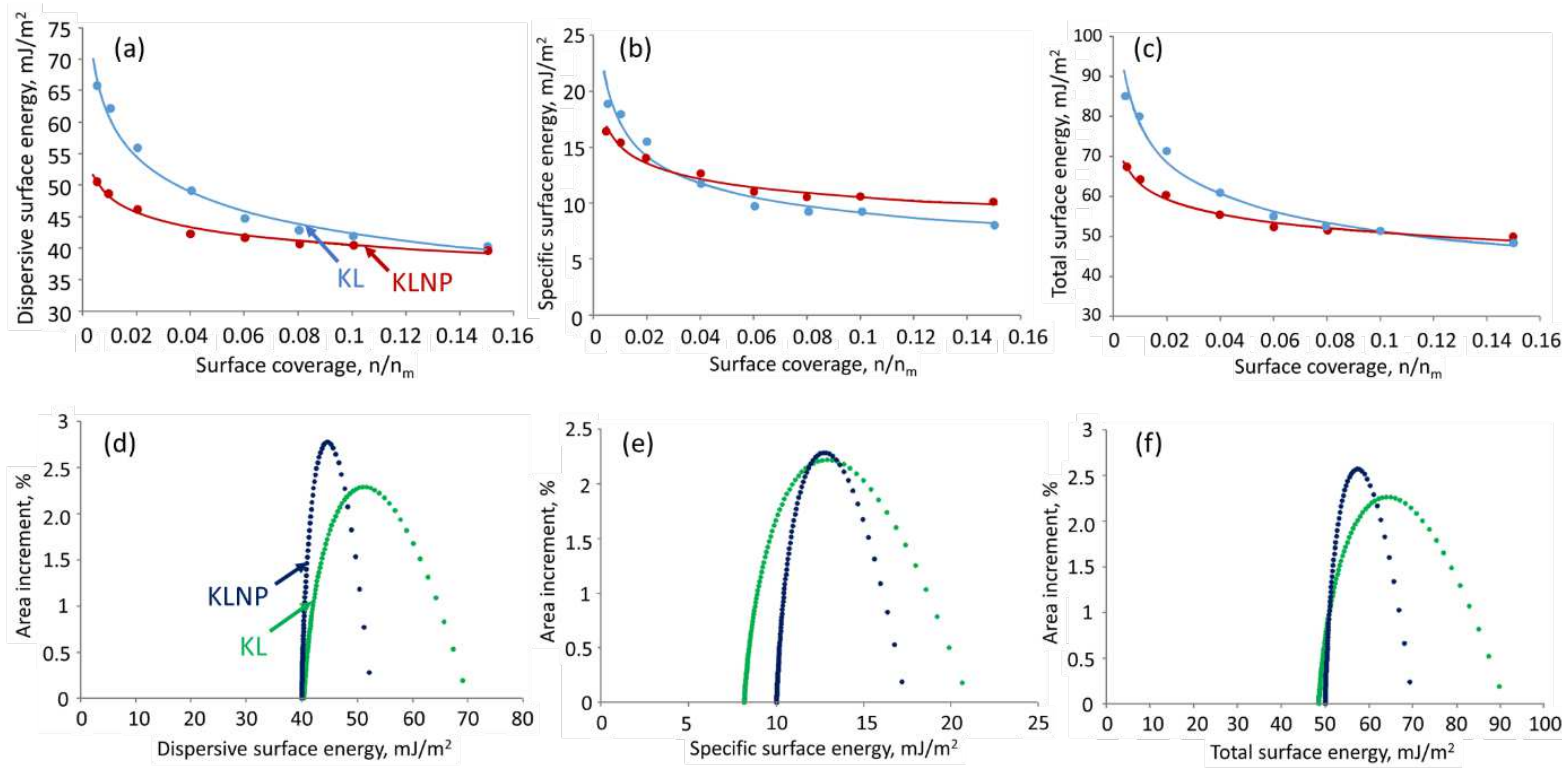

Figure 2. Comparative plots of the surface properties of KL and KLNP for their surface energies versus percentage of surface area (a) Dispersive surface energy, (b) Specific surface energy, and (c) Total surface energy and the plots of surface energy versus percentage of surface (area increment) (d) Dispersive surface energy, (e) Specific surface energy, and (f) Total surface energy.

All the profiles show that both KL and KLNP are energetically heterogeneous, which means

242 that surface energy changes as a function of surface coverage. In addition, it can be clearly

243 observed that the dispersive component contributes to a major part of the surface energy. The combined plot of dispersive, specific (acid-base) and the total surface energy of the samples are presented in Figure 2a-2c. The narrower profile of the total surface energy of KLNP,

246 ranging from 50 to $69 \mathrm{~mJ} / \mathrm{mm}^{2}$, indicates that such sample is more energetically homogeneous

247 than KL. This highlights that the surface structure caused by isotropic shrinking during 248 regeneration (drying) from the precursor solution resulted in a solidified and perfectly spherical 249 shapes with atomic/molecular reconstruction on the surface. This energy homogeneity may 250 provide more stable flow behavior of KLNP. KL is relatively more heterogeneous, 251 possessing surface sites with different energy levels; hence, KL is more active, having higher 252 dispersive and total surface energy. In order to represent the heterogeneity of these samples, 
253 the surface energy distributions are obtained by a point - by - point integration of the surface

254 energy profiles, resulting in plots of $\gamma_{\mathrm{s}}^{\mathrm{D}}, \gamma_{\mathrm{s}}^{\mathrm{AB}}$, and $\gamma_{\mathrm{s}}^{\mathrm{T}}$, surface energy versus percentage of 255 surface (area increment), as shown in Figure 2d-2e. The y50, the median, has been defined as 256 the surface energy where half of the population lies below this value. Similarly, 90 percent of 257 the distribution lies below the y90, and 10 percent of the population lies below the y10 (Table 258 S2). The specific (acid-base) Gibbs free energy of desorption, $\Delta G_{S P}$, of polar solvents on both 259 samples was also measured at different surface coverage (Figure $3 \mathrm{a}, 3 \mathrm{~b}$ ). The $\Delta G_{S P}$ profiles as 260 a result of the interaction with all five or six polar probe molecules are displayed. Higher $\Delta G_{S P}$ 261 values can be attributed to a higher concentration of polar surface groups or different surface 262 groups with higher specific surface energy. Both KL and KLNP showed strong degree of interactions with all the polar probes and the rank of order of KL for decreasing $\Delta G_{S P}$

264 interactions goes in the order acetonitrile, ethanol, dichloromethane, chloroform, and toluene 265 and for KLNP, as ethanol, dichloromethane, chloroform and toluene. The surface chemistry of 266 the samples was assessed using the Gutmann acid $\left(K_{a}\right)$ and base $\left(K_{\mathrm{b}}\right)$ numbers, determined with 267 polar probes (dichloromethane, toluene, chloroform, ethanol, and chloroform). $K_{a}$ and $K_{\mathrm{b}}$ 268 values of the samples were calculated using the $\Delta G_{S P}$ values of polar probes at that particular 269 surface coverage. 

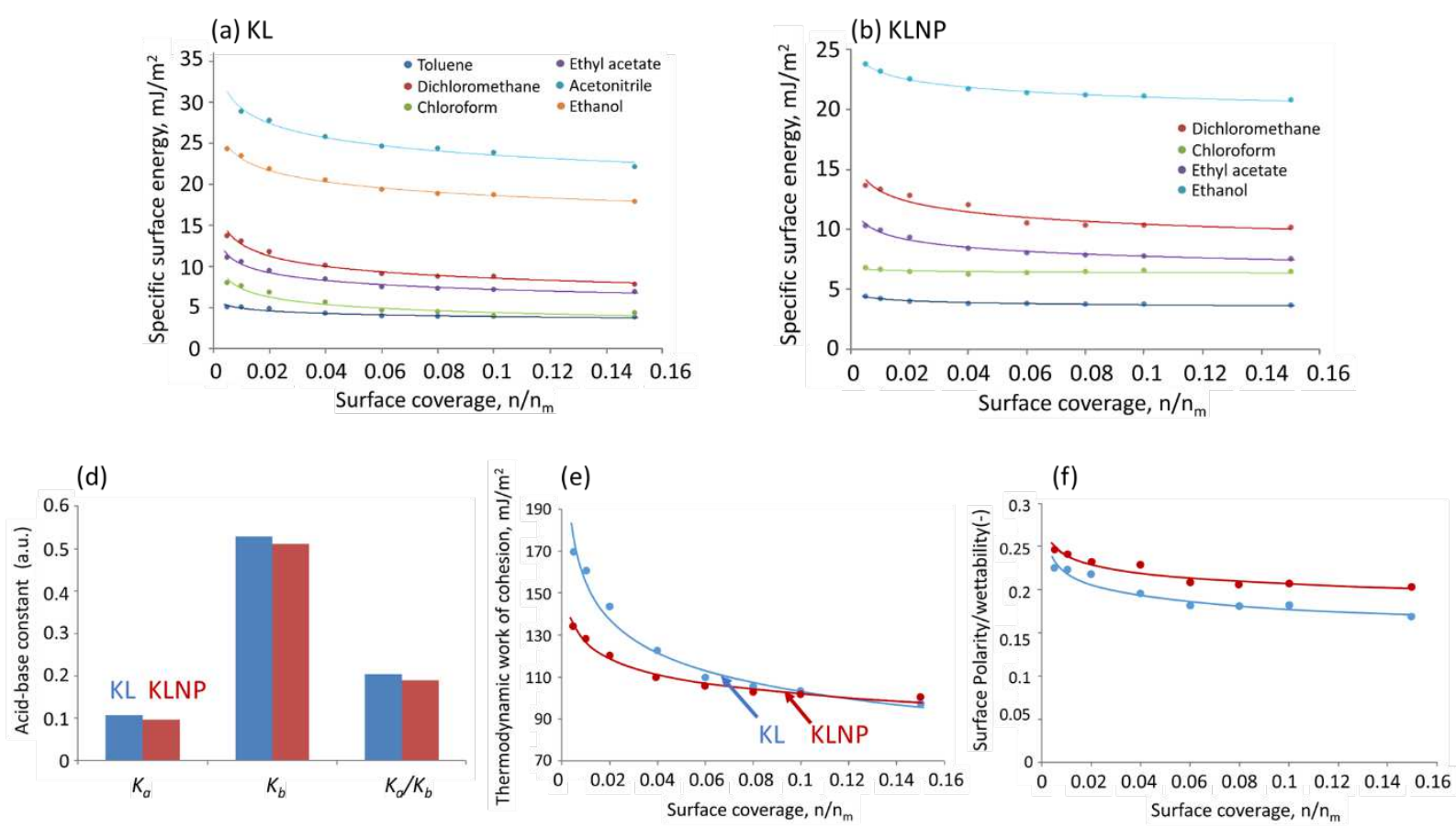

272 Figure 3. Specific free surface energy against area increment for (a)KL and (b) KLNP showing

273 strongest interactions with the polar probes. (c) The Gutmann acid $\left(K_{a}\right)$ and base constants

$274\left(K_{b}\right)$ at a surface coverage of $0.005 \mathrm{n} / \mathrm{n}_{\mathrm{m}}$, (d) Thermodynamic work adhesion, and (e) Surface 275 polarity/Wettability for KL and KLNP.

278 Figure $3 \mathrm{~d}$ shows the $K_{\mathrm{b}}$ for both samples was consistently higher than $K_{a}$, indicating that the samples possess higher concentrations of electron-donating (basic) surface functional groups

280 than electron-withdrawing (acidic) ones. Surface energy is directly related to the

281 thermodynamic work of adhesion between two materials, which corresponds to the work

282 required to reversibly separate an interface between two bulk phases. The total work of 283 cohesion was determined according to geometric mean methods, as shown in Figure 3d. KL

284 showed higher work of cohesion, which also indicated high tendency of aggregation in the samples compared to KLNP. The polarity of both samples, KL and KLNP was calculated from

286 the specific and total surface energies, shown in Figure $3 \mathrm{f}$. The results suggest that KLNP is

287 relatively more polar and hydrophilic compared to KL. This result indicates that many critical functional groups in the lignin molecule, such as phenolic/aliphatic hydroxyl groups, alkyl-aryl 
ether group, etc., can be exposed on the particle surface, thus allowing further chemical modifications effectively. More detailed surface composition analysis may be performed by 1HNMR measurements(Pylypchuk et al. 2020) in combination with IGC. The surface properties of KLNP, with its energetical homogeneity and hydrophilicity, should play an important role in enhancing interfacial interactions, such as good dispersibility the particles and interfacial adhesion between KLNP and polymer matrices in composites.

KL and KLNP were applied as reinforcing fillers in unsaturated polyester resin to identify the impact of the size, the morphology, and the surface properties of KLNP on the mechanical and the electrical properties of the UPE-based composites. Figure 5 shows the results from the bending tests for KL or KLNP/UPE composites with different KL and KLNP loadings.
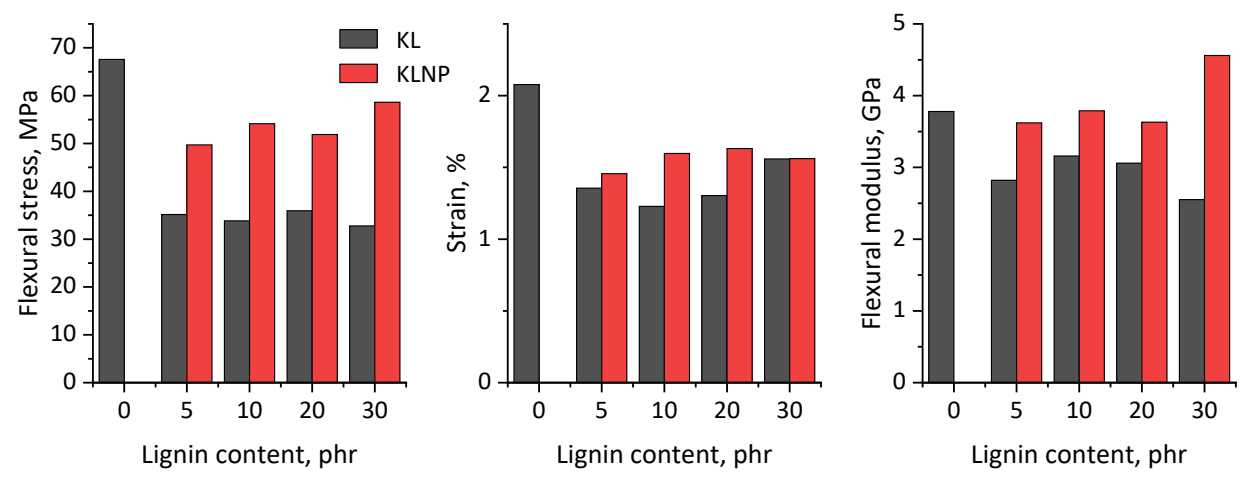

Figure 4. The mechanical properties of the KL or KLNP/UPE composites with different lignin addition (a) Flexural stress, (b) Strain, and (c) Flexural modulus.

The flexural strength for the KL/UPE composites dropped to nearly half of the reference polyester sample, from 68 to $35 \mathrm{MPa}$ with the addition of KL with $5 \mathrm{phr}$ of the matrix polymer.

307 The values hardly changed when KL was increased up to $30 \mathrm{phr}$. When KLNP was incorporated in the polymer matrix, the decrease in flexural strength was suppressed; it even slightly increased to up to $59 \mathrm{MPa}$ at $30 \mathrm{phr}$ KLNP, Figure 4a. 
310 The flexural strength, e.g., the capacity of a material to resist the bending force applied

311 perpendicular to its longitudinal axis, indicated a good dispersity of KLNP, with no significant

312 aggregation in the matrix. This is examined by the energetical homogeneity of the surfaces (see

313 Figure 2 and 3). Another reason for the improvement of the flexural strength might be ascribed

314 to the good mechanical strength of KLNP particles, due to the formation of extended networks

315 intra- or inter molecular interactions, compared to KL powder, which consisted of undefined

316 shapes with secondary particle agglomeration.

317 The flexural strain was considerably decreased with increasing of KL or KLNP loading shown

318 in Figure 4b. As the strain is reciprocal to the stiffness of a material, the results show that the

319 filler imparts a greater stiffening effect. It can be seen that by addition of 5 phr KL or KLNP, 320 the strain dropped to approximately $65 \%$ and $70 \%$, respectively. The reduction in strain at 321 break implies that the ductility of the matrix was suppressed by the presence of the filler. The composites with KLNP showed a slightly higher ductility than the one with KL. The flexural modulus of the KL and KLNP/UPE composites are shown in Figure 4c. For KLNP/UPE

324 composites, the elastic moduli were also increased with KLNP content and the highest value, 4.6 GPa, was achieved at $30 \mathrm{phr}$ KLNP. However, when KL were incorporated, it decreased to 2.6 GPa at the same concentration. Morphological analysis of the KL and KLNP/UPE composites. SEM was used to study the morphology and microstructure of the KL and KLNP/UPE composites. Figure 5 shows the

329 SEM micrographs of the fractured surface of composites with different amounts of KL and

330 KLNP. The fracture surface of the KL composites was observed to be very rough in the lignin

331 filler domains and with many voids. By contrast, KLNP composites shoed relatively smooth

332 fractures and well defined spherical KLNP domains. It can be seen that KL and KLNP particles 333 were under the stress concentration against force loading.(Ngo et al. 2019) It is noticeable that 
334 KLNP was well dispersed, with no significant aggregates in the matrix and regardless of 335 loading.

336
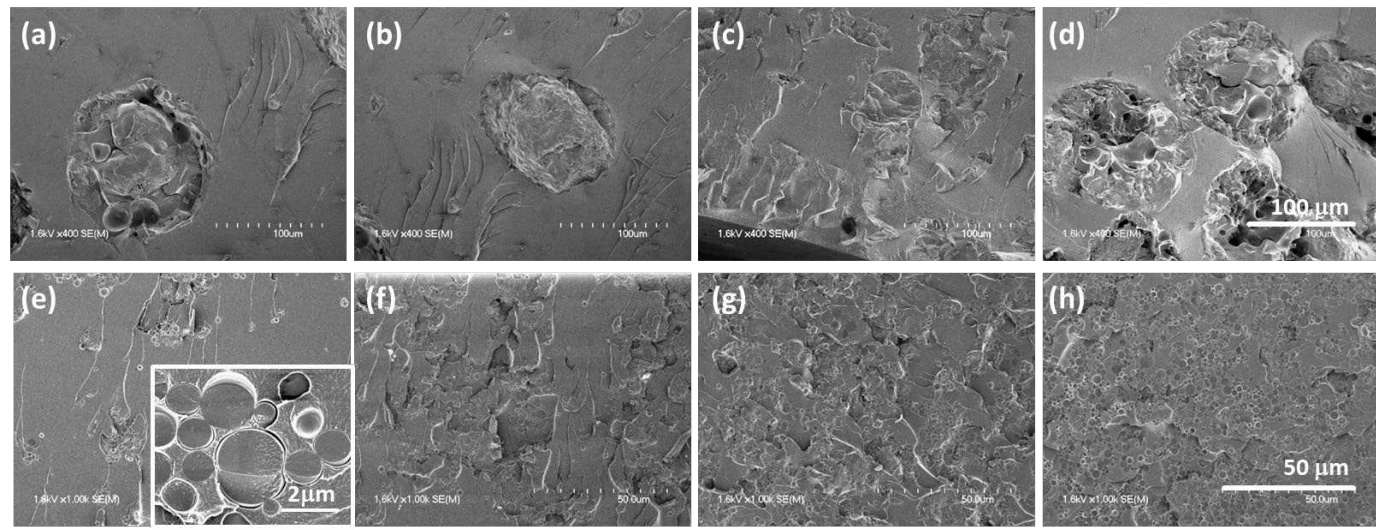

337

338 Figure 5. Scanning electron micrographs of the fractural surface for (a)-(d) KL/UP and (e)-(h) $339 \mathrm{KLNs} / \mathrm{UP}$ composites with different the filler contents (a, e) $5 \%$, (b, f) $10 \%$, (c, g) $20 \%$, and 340 (d, h) $30 \%$. Scale bar for (a) - (d), $100 \mu \mathrm{m}$, for (e) - (h), $50 \mu \mathrm{m}$.

341

342 The homogeneous morphology observed in KLNP/UPE composites should be reflected in the

343 improvement in flexural strength and modulus, as mentioned above. In the higher

344 magnification of the fractural surface of KLNP/UPE composites, gaps at the interface between

345 KLNP and the matrix polymer were clearly observed, which indicates poor interfacial adhesion

346 (Figure 5, insert). This interfacial phenomenon is consistent with the surface energy of KLNP,

347 which was shown to be hydrophilic compared to KL (gas inverse chromatography, Figures 2

348 and 3). In order to improve the adhesion at the interface between KLNP and the matrix

349 polymer, trichlorovinylsilane was used as a coupling agent. FT-IR studies for the particles after

350 the silane treatment confirmed the occurrence of new bands around $2950,2897 \mathrm{~cm}^{-1}$ for $\mathrm{CH}_{2}$

351 stretching $1720 \mathrm{~cm}^{-1}$ for vinyl groups, at 770, $1152 \mathrm{~cm}^{-1}$ for Si-O-Si from the hydrolysis

352 condensation reaction, that confirmed successfully introduction of the siloxane with vinyl

353 group on the surface of the particles, V_KLNPS (Figure S2).(Kanimozhi et al. 2014) Further

354 investigation was conducted by SEM and EDX measurements. SEM micrographs of the 
particles after the silane treatment showed well-defined polysiloxane nanofilaments grown on the surface.(Artus et al. 2006)' (Rollings et al. 2007) The typical length and diameter of the nanofilaments were $500 \mathrm{~nm}$ and $30 \mathrm{~nm}$, respectively. Such nanostructure on the surface was responsible for the superhydrophobicity, as expected (Figure S2). EDX confirmed the presence of silicon on the surface (Figure 6). In addition, we confirmed a polysiloxane thin layer across the surface of the particles (see SEM image of the resulting the thin films collapsing onto the substrate after the removal of lignin dissolution). The thin film of polysiloxane with a size of a polysiloxane thin layer, uniformly deposited over the surface of every particle, regardless its size (Figure 6c). Similar nano-structured material, with a hollow thin film induced by
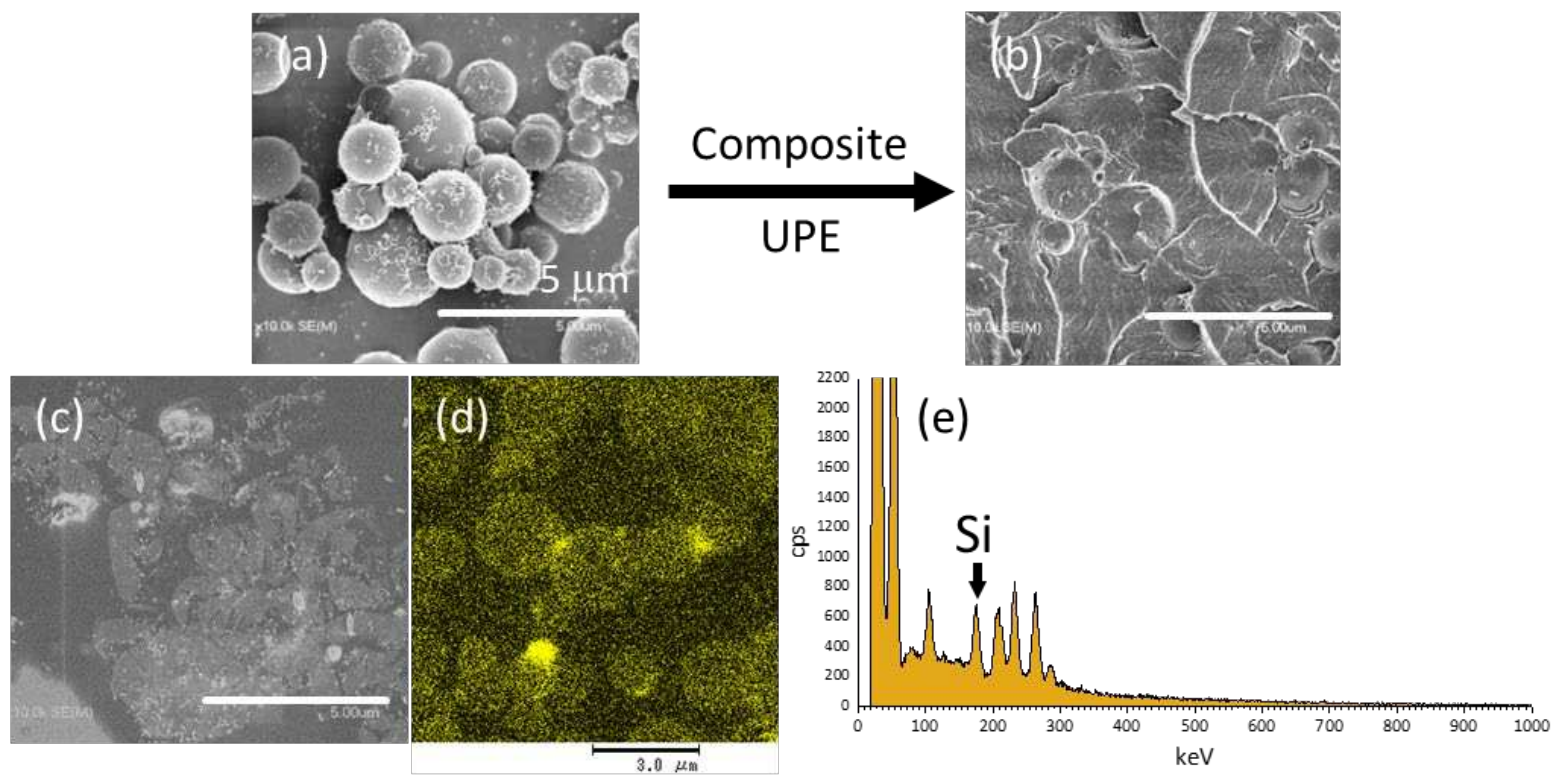

Figure 6. Scanning electron micrographs of (a) V_KLNP modified with silane, (b) V_KLNP/UPE composites with 10 phr of the filler, (c) The polysiloxane thin layers collapsing onto the substrate after the removal of lignin dissolution. EDX spectra detected Si for (d) the mapping image and (e) the spectrum. 
V_KLNP/UPE composite at $10 \mathrm{phr}$ filler content was prepared by the same procedure as explained for KLNP. As can be seen in Figure S2, some V_KLNP aggregated in the matrix, which may result from the drying process of the particles, from water/toluene suspension, 377 followed by rinsing after silane treatment. This highlights that the redispersion of V_KLNP

378 from the dry state into a polymer resin, with less aggregation, may require severe redispersion 379 steps such as high shearing. In the high magnification mage of Figure 6 , the interaction between the fillers and the matrix polymer was significantly improved. No air gaps were observed at the interface. This result suggests that V_KLNP fillers efficiently formed covalent bonds, via vinyl groups, with the matrix polymer and during the curing process. Additionally, since the surface of V_KLNP became superhydrophobic, as already discussed, they had the tendency to interact with the hydrophobic polymer matrix. The enhancement of the interfacial adhesion may lead to improvements in the thermomechanical and dielectric properties of the composites, as will be discussed later. The improvement of interfacial adhesion has been reported for Kraft lignin and UPE and the effect of lignin on volume shrinkage and mechanical properties has been investigated.(Yeo et al. 2017)

389 TGA-DTA measurements were carried out to determine the thermal stability of the composites, at different loading and surface properties of the fillers. The temperatures at $5 \%$ weight loss, $T_{5 \%}$ and at the maximum rate of weight loss, $T_{\mathrm{d}}$ of the composites were determined

392 from the TG thermographs and summarized in Figure 7. Compared to neat UPE, $T_{5 \%}$ were 393 found to be gradually decreased as the filler content increased (both for KL or KLNP). However, 394 the $T_{5 \%}$ of the KL/UPE composites decreased as the filler content increased, while the decrease 395 of the $T_{5} \%$ of the KLNP/UPE composite was suppressed. This can explain the high thermal stability of KLNP, with excellent mechanical integrity resulting from intra- and intermolecular

397 interaction formed during the aerosol regeneration (drying) process.(Ago et al. 2016a) 398 V_KLNP/UPE (10 phr filler content) improved the thermal stability at $T_{5 \%}$ and $T_{\mathrm{d}}, 310$ and 
$377{ }^{\circ} \mathrm{C}$, respectively in comparison to $\mathrm{KL}$, or KLNP/UPE composites. Th results can be 400 explained from the strong interaction between V_KLNP and the matrix as well as the higher 401 bond energy of Si-O bonds, consisting of a polysiloxane layer, as opposed to that of C-C or C402 O bonds.(Kumar and Narayanan 2002) In addition, no air gaps were observed at the interface 403 between KL or KLNP and UPE in the composites, given the better interfacial adhesion, which 404 resulted in a restricted enhancement of thermal conductivity of the composites.

405

406

407

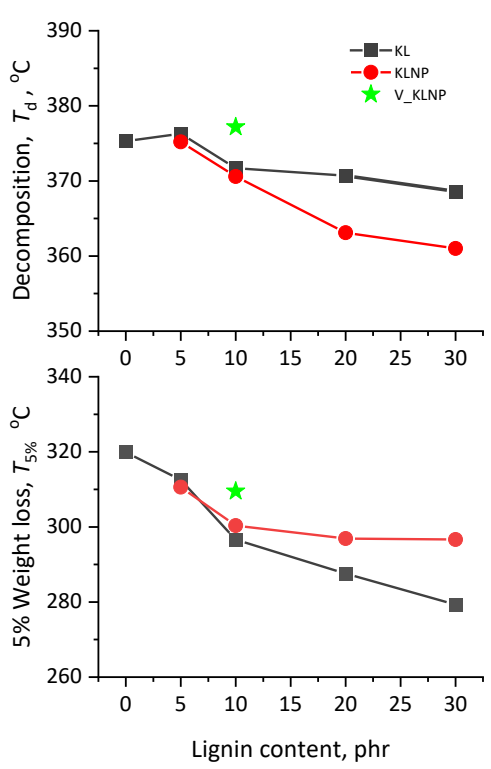

408

409 Figure 7. TG thermographs for KL or KLNP/UPE composites with different loading of the 410 filler content from 0 to $30 \mathrm{phr}$ and the star indicates $T_{5 \%}$ or $T_{\mathrm{d}}$ from V_KLNP/UPE composites 411 with $10 \mathrm{phr}$ of the filler content.

412

413

414 The composites filled with the lignin spherical particles, KLNP and V_KLNP, were tested 415 next as wave-transparent materials, towards $5 \mathrm{G}$ high-speed communication devices, which can 416 transmit electromagnetic waves at a certain frequency. Therefore, the dielectric properties in 417 the millimeter frequency region of the composites were examined. Wave-transparent 
418 materials require a low permittivity, $\varepsilon_{\mathrm{s}}$ and dielectric loss tangent, $\tan \delta\left(\varepsilon_{\mathrm{s}}\right.$ and $\tan \delta$ decreases

419 the electromagnetic wave loss also reduced during transmission).(Wang et al. 2020) The 420 electromagnetic loss is mainly due to the polarization phenomenon of the medium in the 421 external electric filed, i.e. electric polarization, atomic polarization, ionic polarization, orientation polarization, and interfacial polarization.(Wang et al. 2020) In order to achieve low $\varepsilon_{\mathrm{s}}$ and $\tan \delta$ in the nanocomposites, it is important to reduce interfacial polarization by 424 improving the interfacial adhesion between the filler and the matrix. The permittivity of V_KLNP/UPE composite (10 phr V_KLNP content) improved the permittivity, $\varepsilon_{\mathrm{s}} 2.75$ (at 28 $\mathrm{GHz}$ ) compared to the KLNP/UPE composite, $\varepsilon_{\mathrm{s}}, 3.01$, which can result from better interaction between V_KLNP and the matrix. We note that the low polarity of $\mathrm{Si}-\mathrm{O}$ bonds in the polysiloxane structure also contribute to a reduction in permittivity. A dielectric loss, $\tan \delta$ of 0.01 was measured for both samples, which can fit the demands of the intended application. The results of the dielectric properties of KLNP and V_KLNP composites are in the range of commonly used polymers and fillers (Table S3 (Ávila et al. 2013) (Krishnadevi et al. 2013)).

\section{Conclusion}

434 We demonstrate the synthesis the spherical lignin nano-, micro- particles with a continuous aerosol process for pursuing mass-production of lignin nano- and microparticles using Kraft lignin/DMF solution. We investigated the effective yield for various particle sizes and distributions as a function of concertation of the precursor solution. It was found that $5 \%$ lignin content in the precursor solution provided good yield, with narrower particle distribution. The lignin particles were perfectly spherical and smooth, in the range size from 0.85 to $1.57 \mu \mathrm{m}$.

440 Inverse gas chromatography determined the surface energy of the spherical lignin nano-, micro441 particles. KLNP showed a relatively high polarity and a higher hydrophilicity compared to KL. 442 This result suggests that many critical functional groups, such as phenolic/aliphatic hydroxyl 
groups, alkyl-aryl ether group, among others, are exposed on the particle surface. Importantly,

444 total surface energy of KLNP indicated that it is more energetically homogeneous than KL.

445 Therefore, spherical lignin particle formation may be adopted as a new class of lignin materials

446 to overcome diversity at the molecular level. We applied lignin nano- micro-particles as fillers

447 in unsaturated polyester composites, which were tested for their dielectric properties in the

448 millimeter frequency, valuable in the design of next-generation 5G high-speed materials. The

449 obtained KLNP composites exhibited $\varepsilon$ and $\tan \delta$ values of 3.01 and 0.01 at $28 \mathrm{GHz}$. Further,

$450 \varepsilon, 2.75$ was improved by improving interfacial interaction via silane treatment of KLNP.

451 Overall, the results highlight that KLNP/UPE and V_KLNP/UPE composites display

452 performance benefits for wave-transparent materials at extremely high frequency. We believe

453 that the results of this study will help increase the value of lignin. Although lignin is a natural, 454 biodegradable polymer, a systematic evaluation of size-dependent toxicity should be conducted.

\section{Acknowledgements}

The authors acknowledge funding support by JSPS KAKENHI Grant Number JP 19 K 23

688 and $21 \mathrm{~K} 05156$ (MA). The authors are thankful to Mis Kiyoko Kawashima for operating the EDX in Collaborative Research Center, Meisei Univeristy, also gratefully acknowledge Prof. Tetsuo Kondo, Kyusyu University for continuous discussions. We also Koyama, Meisei Univeristy for discussions.

\section{Declarations}


The authors have no conflicts of interest to declare that are relevant to the content of this article.

467

468

469

470

471

472

473

474

475

476

477

478

479

480

481

482

483

484

485

486

487

488

489

490

491

492

493

494

495

496

497

498

499

500

501

502

503

504

505

506

507

508

This article does not contain any studies involving either animals or human participants performed by any of the authors.

\section{References}

Abbati de Assis C, Greca LG, Ago M, et al (2018) Techno-Economic Assessment, Scalability, and Applications of Aerosol Lignin Micro- and Nanoparticles. ACS Sustain Chem Eng 6:11853-11868. https://doi.org/10.1021/acssuschemeng.8b02151

Ago M, Huan S, Borghei M, et al (2016a) High-throughput synthesis of lignin particles ( $\sim 30$ $\mathrm{nm}$ to $\sim 2000 \mathrm{~nm}$ ) via aerosol flow reactor: Size fractionation and utilization in pickering emulsions. ACS Appl Mater Interfaces 8:23302-23310. https://doi.org/10.1021/acsami.6b07900

Ago M, Huan S, Borghei M, et al (2016b) High-Throughput Synthesis of Lignin Particles ( $30 \mathrm{~nm}$ to $\sim 2 \mu \mathrm{m}$ ) via Aerosol Flow Reactor: Size Fractionation and Utilization in Pickering Emulsions. ACS Appl Mater Interfaces 8:23302-23310. https://doi.org/10.1021/acsami.6b07900

Ago M, Tardy BL, Wang L, et al (2017) Supramolecular assemblies of lignin into nano- and microparticles. MRS Bull 42:371-378. https://doi.org/10.1557/mrs.2017.88

Artus GRJ, Jung S, Zimmermann J, et al (2006) Silicone nanofilaments and their application as superhydrophobic coatings. Adv Mater 18:2758-2762

Ávila HA, Ramajo LA, Góes MS, et al (2013) Dielectric Behavior of Epoxy/BaTiO3 Composites Using Nanostructured Ceramic Fibers Obtained by Electrospinning. ACS Appl Mater Interfaces 5:505-510. https://doi.org/10.1021/am302646z

Beaumont M, Kondor A, Plappert S, et al (2017) Surface properties and porosity of highly porous, nanostructured cellulose II particles. Cellulose 24:435-440

Belgacem MN, Czeremuszkin G, Sapieha S, Gandini A (1995) Surface characterization of cellulose fibres by XPS and inverse gas chromatography. Cellulose 2:145-157

Berlin A, Balakshin M (2014) Chapter 18 - Industrial Lignins: Analysis, Properties, and Applications. In: Gupta VK, Tuohy MG, Kubicek CP, et al. (eds). Elsevier, Amsterdam, pp 315-336

Blattmann CO, Pratsinis SE (2019) Nanoparticle Filler Content and Shape in Polymer Nanocomposites. KONA Powder Part J 36:3-32. https://doi.org/10.14356/kona.2019015

Chakar FS, Ragauskas AJ (2004) Review of current and future softwood kraft lignin process chemistry. Ind Crops Prod 20:131-141

Frangville C, Rutkevičius M, Richter AP, et al (2012) Fabrication of environmentally biodegradable lignin nanoparticles. ChemPhysChem 13:4235-4243. https://doi.org/10.1002/cphc.201200537

Fritz C, Salas C, Jameel H, Rojas OJ (2017) Self-association and aggregation of kraft lignins via electrolyte and nonionic surfactant regulation: stabilization of lignin particles and effects on filtration. Nord Pulp Pap Res J 32:572-585

Gierer J (1980) Chemical aspects of kraft pulping. Wood Sci Technol 14:241-266. https://doi.org/10.1007/BF00383453 
Gilca IA, Popa VI, Crestini C (2015) Obtaining lignin nanoparticles by sonication. Ultrason Sonochem 23:369-375

Glasser WG (2019) About Making Lignin Great Again-Some Lessons From the Past. Front Chem 7:565. https://doi.org/10.3389/fchem.2019.00565

$\mathrm{Hu}$ Y, Ishikawa K (2020) Ultrahigh dielectric constant induced by the interfacial polarization between liquid crystal droplets and polymer matrix. Jpn J Appl Phys 59:60901. https://doi.org/10.35848/1347-4065/ab8f16

Kai D, Tan MJ, Chee PL, et al (2016) Towards lignin-based functional materials in a sustainable world. Green Chem 18:1175-1200. https://doi.org/10.1039/C5GC02616D

Kämäräinen T, Ago M, G. Greca L, et al (2019) Morphology-Controlled Synthesis of Colloidal Polyphenol Particles from Aqueous Solutions of Tannic Acid. ACS Sustain Chem \&amp; Eng 7:16985-16990. https://doi.org/10.1021/acssuschemeng.9b02378

Kanimozhi K, Prabunathan P, Selvaraj V, Alagar M (2014) Vinyl silane-functionalized rice husk ash-reinforced unsaturated polyester nanocomposites. RSC Adv 4:18157-18163

Khan I, Saeed K, Khan I (2019) Nanoparticles: Properties, applications and toxicities. Arab J Chem 12:908-931. https://doi.org/https://doi.org/10.1016/j.arabjc.2017.05.011

Klapiszewski L, Jamrozik A, Strzemiecka B, et al (2017) Activation of Magnesium Lignosulfonate and Kraft Lignin: Influence on the Properties of Phenolic Resin-Based

Composites for Potential Applications in Abrasive Materials. Int. J. Mol. Sci. 18

Krishnadevi K, Grace AN, Alagar M, Selvaraj V (2013) Development of hexa (aminophenyl)cyclotriphosphazene-modified cyanate ester composites for hightemperature applications. High Perform Polym 26:89-96. https://doi.org/10.1177/0954008313500058

Kumar SA, Narayanan TSNS (2002) Thermal properties of siliconized epoxy interpenetrating coatings. Prog Org coatings 45:323-330

Lievonen M, Valle-Delgado JJ, Mattinen M-L, et al (2016) A simple process for lignin nanoparticle preparation. Green Chem 18:1416-1422. https://doi.org/10.1039/C5GC01436K

Lloyd DR, Ward TC, Schreiber HP (1989) Inverse gas chromatography. Washington, DC (USA); American Chemical Society

Myint AA, Lee HW, Seo B, et al (2016) One pot synthesis of environmentally friendly lignin nanoparticles with compressed liquid carbon dioxide as an antisolvent. Green Chem 18:2129-2146. https://doi.org/10.1039/C5GC02398J

Ngo T-D, Patenaude E, Ahvazi B (2019) LIGNIN BIO-BASED MATERIAL IN UNSATURATED POLYESTER. Cellul Chem Technol 53:435-448

Nypelö TE, Carrillo CA, Rojas OJ (2015) Lignin supracolloids synthesized from (W/O) microemulsions: use in the interfacial stabilization of Pickering systems and organic carriers for silver metal. Soft Matter 11:2046-2054. https://doi.org/10.1039/C4SM02851A

Österberg M, Sipponen MH, Mattos BD, Rojas OJ (2020) Spherical lignin particles: a review on their sustainability and applications. Green Chem 22:2712-2733. https://doi.org/10.1039/D0GC00096E

Pylypchuk I V, Lindén PA, Lindström ME, Sevastyanova O (2020) New Insight into the Surface Structure of Lignin Nanoparticles Revealed by $1 \mathrm{H}$ Liquid-State NMR Spectroscopy. ACS Sustain Chem Eng 8:13805-13812

Qian Y, Deng Y, Qiu X, et al (2014) Formation of uniform colloidal spheres from lignin $\{$,$\} a$ renewable resource recovered from pulping spent liquor. Green Chem 16:2156-2163. https://doi.org/10.1039/C3GC42131G 
Rao JP, Geckeler KE (2011) Polymer nanoparticles: Preparation techniques and size-control parameters. Prog Polym Sci 36:887-913. https://doi.org/https://doi.org/10.1016/j.progpolymsci.2011.01.001

Rollings DE, Tsoi S, Sit JC, Veinot JGC (2007) Formation and aqueous surface wettability of polysiloxane nanofibers prepared via surface initiated, vapor-phase polymerization of organotrichlorosilanes. Langmuir 23:5275-5278

Sjostrom E (1993) Wood chemistry: fundamentals and applications. Gulf professional publishing

Strzemiecka B, Voelkel A (2012) Estimation of the work of adhesion by means of inverse gas chromatography for polymer complex systems. Int J Adhes Adhes 38:84-88. https://doi.org/https://doi.org/10.1016/j.ijadhadh.2012.05.006

Tang L, Zhang J, Tang Y, et al (2021) Polymer matrix wave-transparent composites: A review. J Mater Sci Technol 75:225-251. https://doi.org/https://doi.org/10.1016/j.jmst.2020.09.017

Tardy BL, Richardson JJ, Guo J, et al (2018) Lignin nano- and microparticles as template for nanostructured materials: formation of hollow metal-phenolic capsules. Green Chem 20:1335-1344. https://doi.org/10.1039/C8GC00064F

van Asten A, van Veenendaal N, Koster S (2000) Surface characterization of industrial fibers with inverse gas chromatography. J Chromatogr A 888:175-196

Wang L, Liu C, Shen S, et al (2020) Low dielectric constant polymers for high speed communication network. Adv Ind Eng Polym Res 3:138-148. https://doi.org/https://doi.org/10.1016/j.aiepr.2020.10.001

Yeo J-S, Lee J-H, Hwang S-H (2017) Effects of lignin on the volume shrinkage and mechanical properties of a styrene/unsaturated polyester/lignin ternary composite system. Compos Part B Eng 130:167-173. https://doi.org/https://doi.org/10.1016/j.compositesb.2017.07.084 

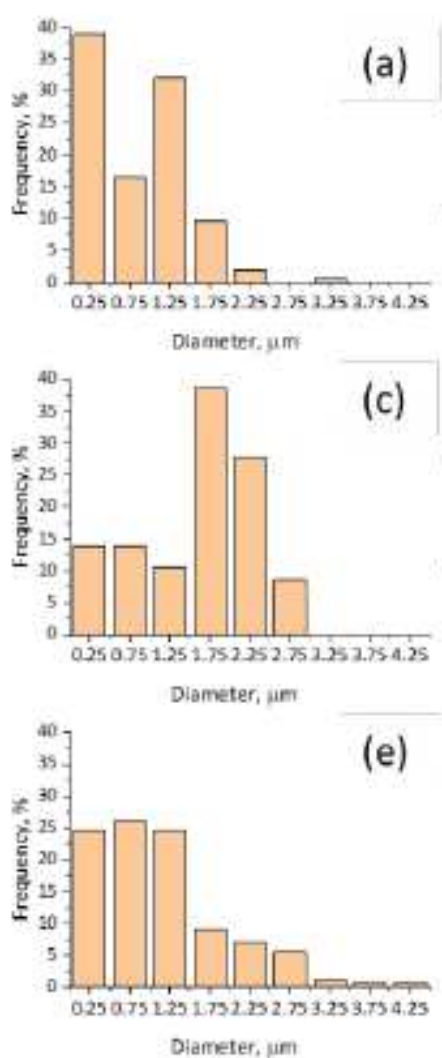
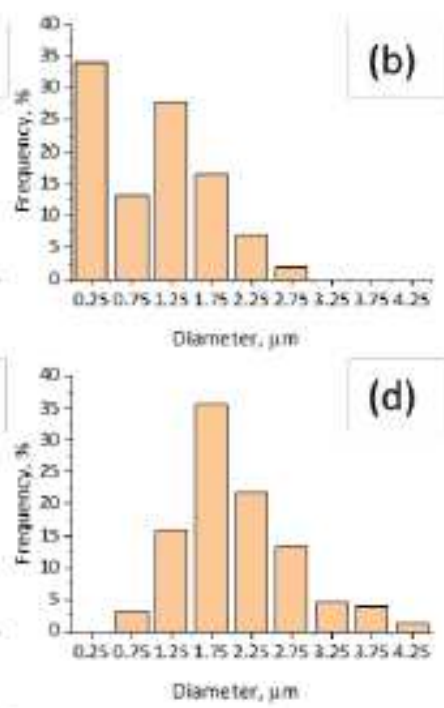

e)
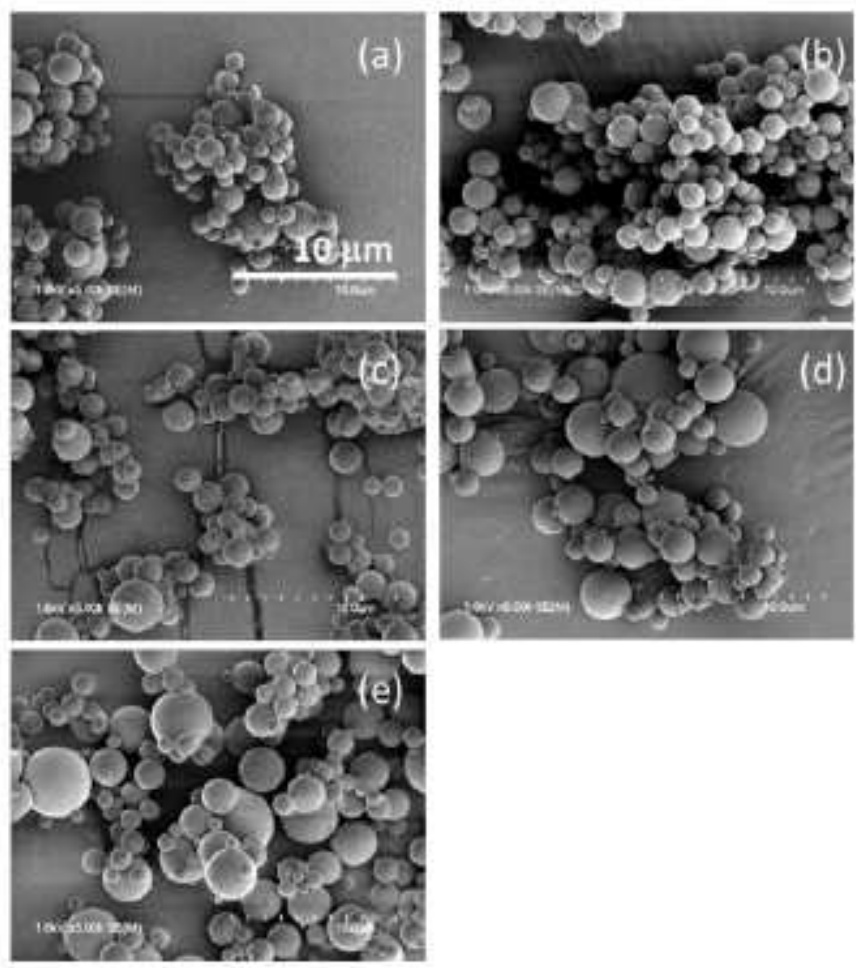

Figure 1

Particle size distribution and SEM micrographs for KLNP obtained from KL precursor solutions at initial concentrations of (a) 1, (b) 3, (c) 5, (d) 7.5, and (e) $10 \%$. Scale bar in SEM images, $10 \mu \mathrm{m}$.
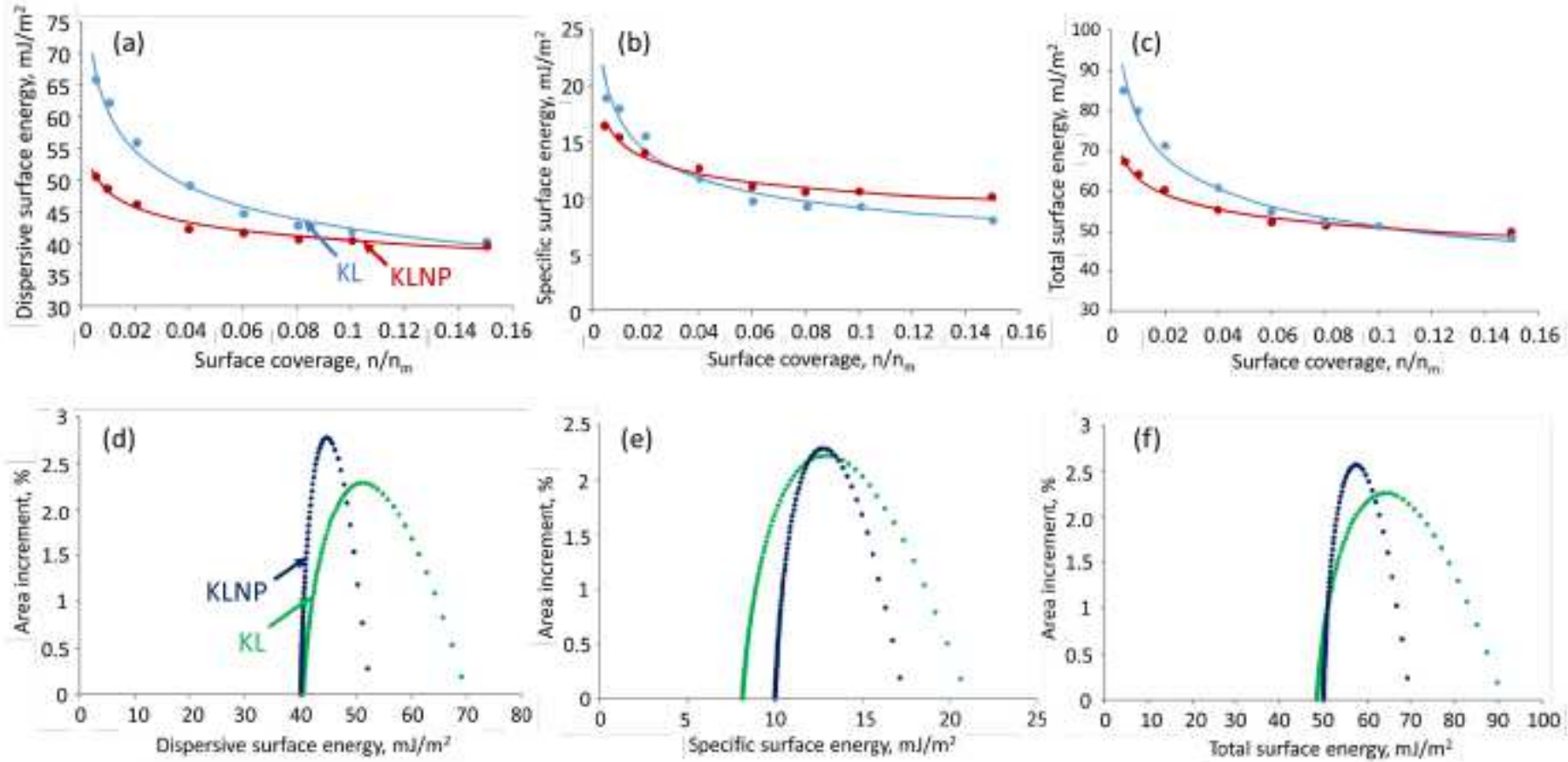
Figure 2

Comparative plots of the surface properties of KL and KLNP for their surface energies versus percentage of surface area (a) Dispersive surface energy, (b) Specific surface energy, and (c) Total surface energy and the plots of surface energy versus percentage of surface (area increment) (d) Dispersive surface energy, (e) Specific surface energy, and (f) Total surface energy.

(a) KL

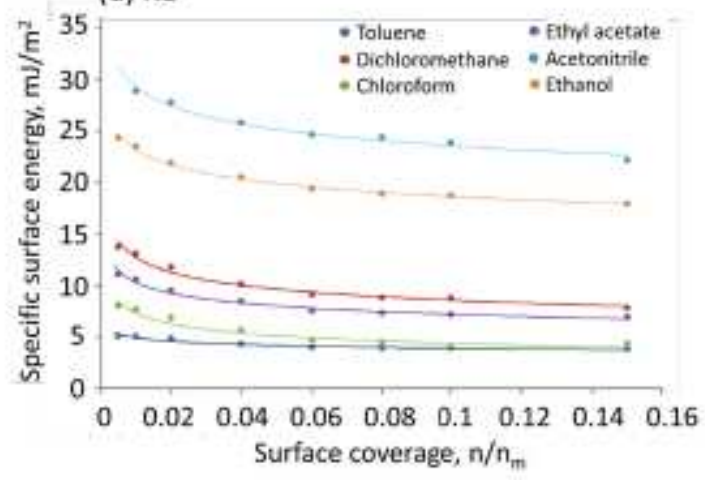

(d)

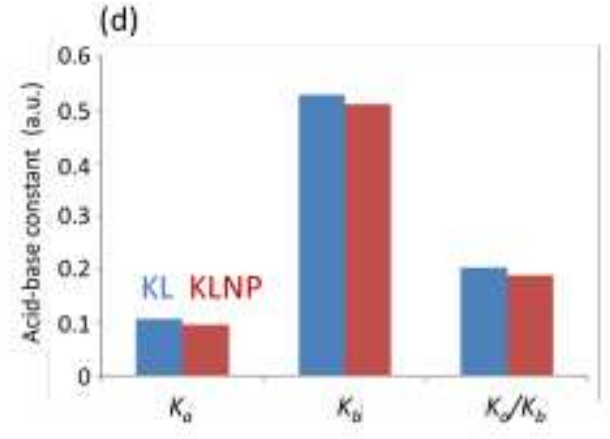

(e)

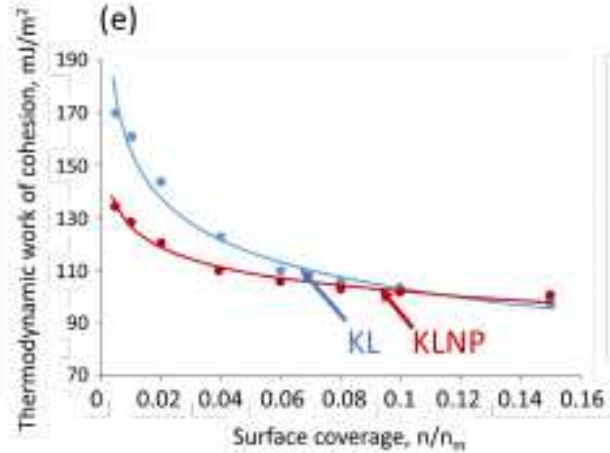

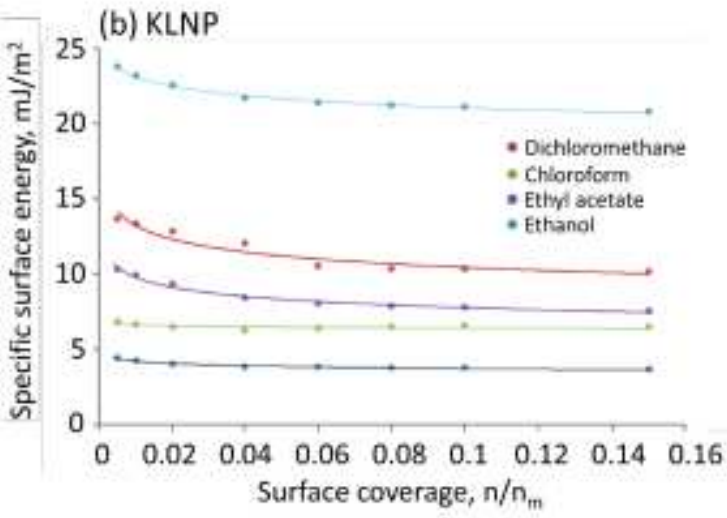

(f)

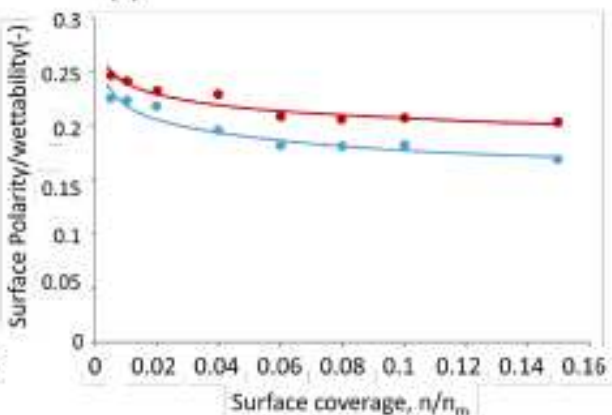

Figure 3

Specific free surface energy against area increment for (a)KL and (b) KLNP showing strongest interactions with the polar probes. (c) The Gutmann acid (Ka) and base constants $(\mathrm{Kb})$ at a surface coverage of $0.005 \mathrm{n} / \mathrm{nm}$, (d) Thermodynamic work adhesion, and (e) Surface polarity/Wettability for KL and KLNP. 

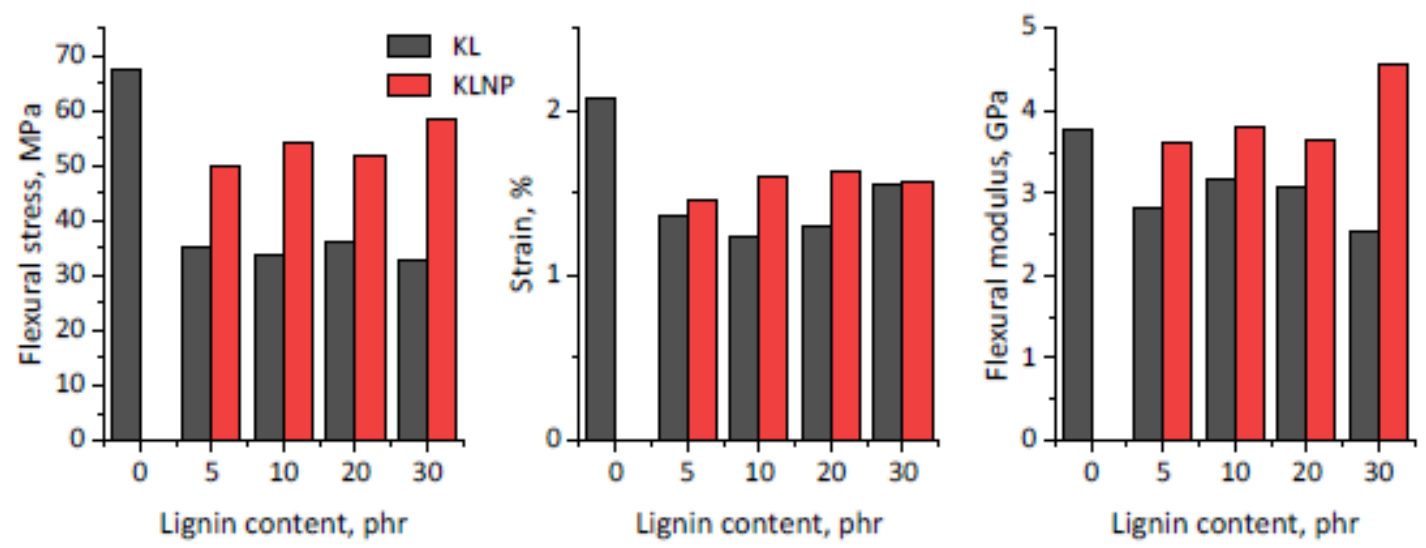

Figure 4

The mechanical properties of the KL or KLNP/UPE composites with different lignin addition (a) Flexural stress, (b) Strain, and (c) Flexural modulus.
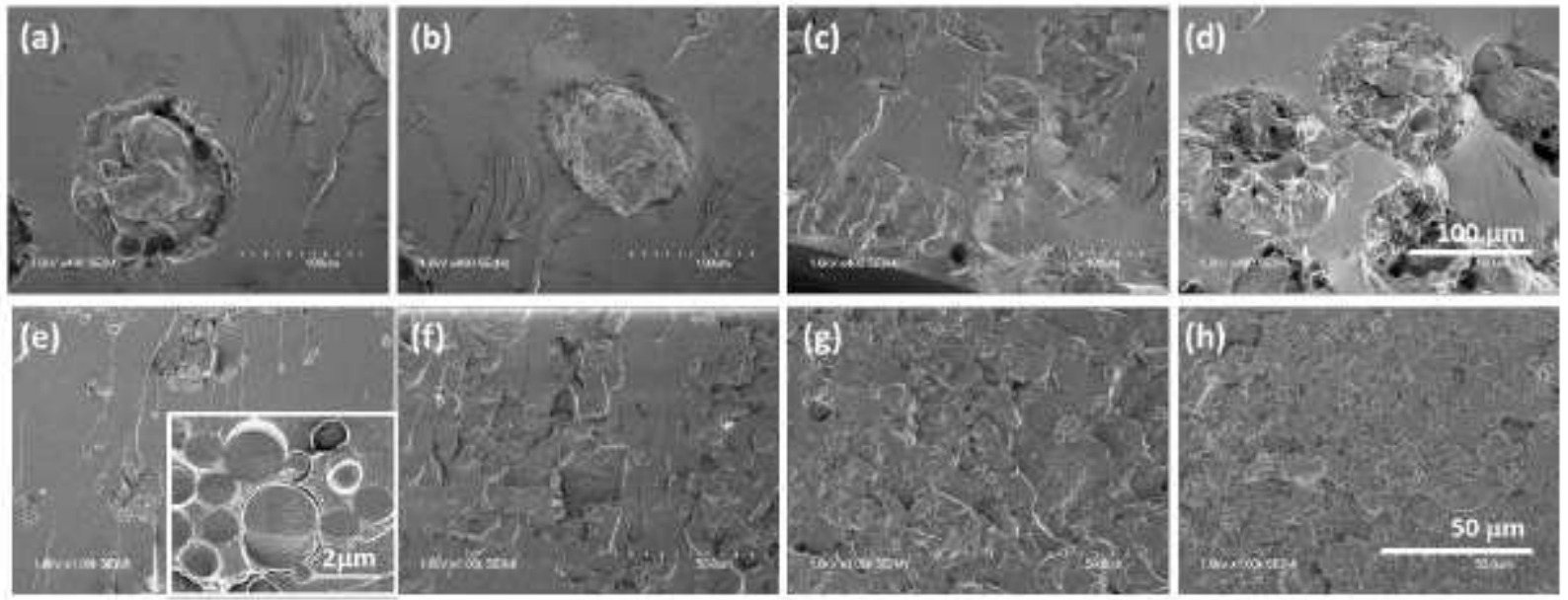

\section{Figure 5}

Scanning electron micrographs of the fractural surface for (a)-(d) KL/UP and (e)-(h) KLNs/UP composites with different the filler contents (a, e) $5 \%$, (b, f) $10 \%$, (c, g) $20 \%$, and (d, h) $30 \%$. Scale bar for (a) - (d), $100 \mu \mathrm{m}$, for $(\mathrm{e})-(\mathrm{h}), 50 \mu \mathrm{m}$. 


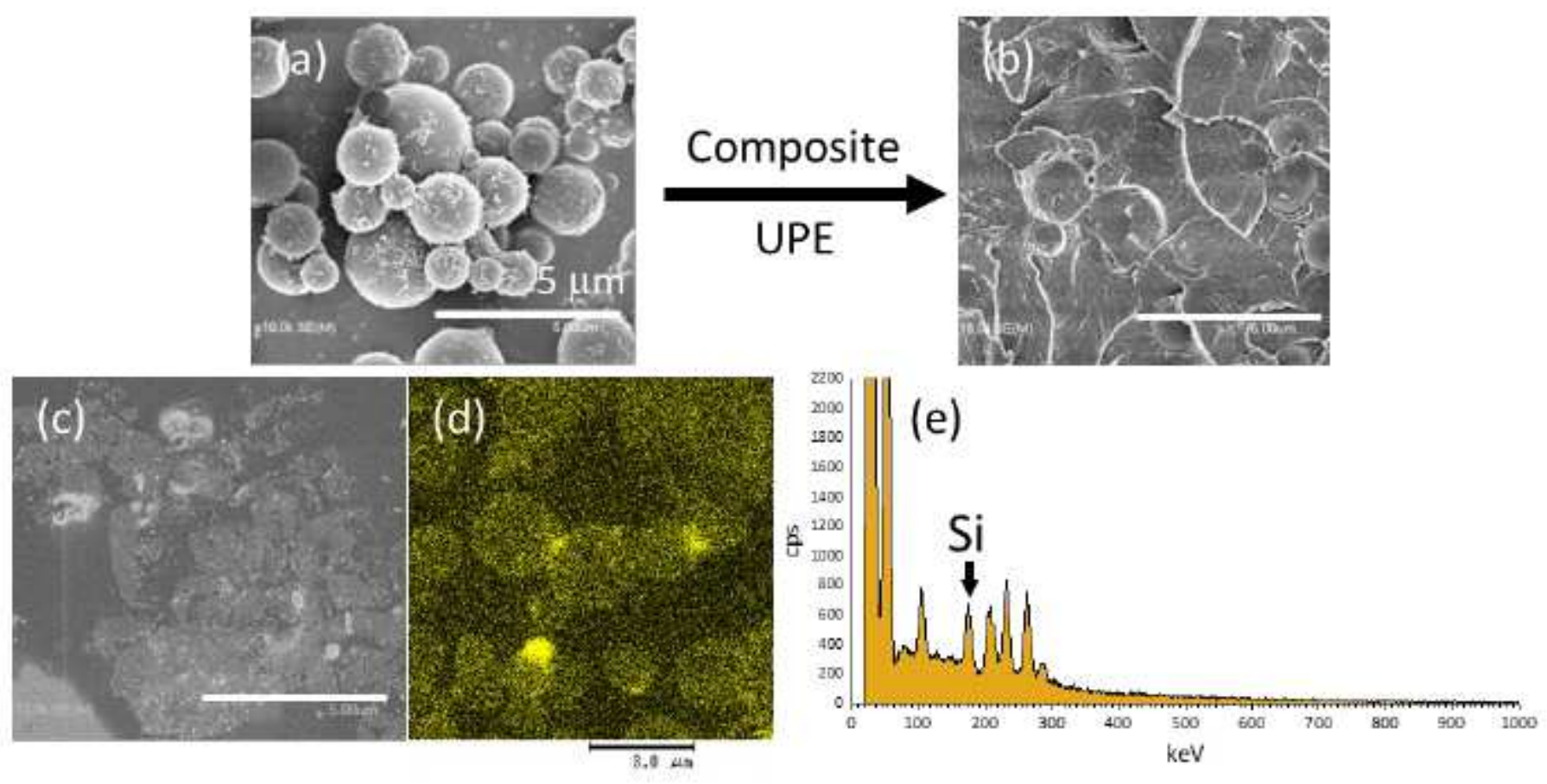

Figure 6

Scanning electron micrographs of (a) V_KLNP modified with silane, (b) V_KLNP/UPE composites with 10 phr of the filler, (c) The polysiloxane thin layers collapsing onto the substrate after the removal of lignin dissolution. EDX spectra detected Si for (d) the mapping image and (e) the spectrum.

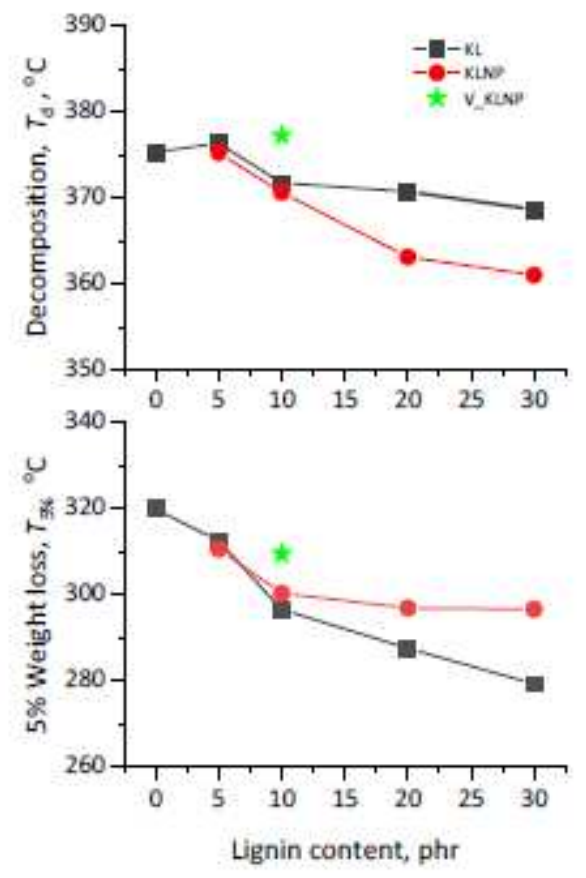

Figure 7 
TG thermographs for KL or KLNP/UPE composites with different loading of the filler content from 0 to 30 phr and the star indicates T5\% or Td from V_KLNP/UPE composites with $10 \mathrm{phr}$ of the filler content.

\section{Supplementary Files}

This is a list of supplementary files associated with this preprint. Click to download.

- SI.pdf 